\title{
Multi-Agent Hybrid Mechanism for Financial Risk Management
}

\author{
Jianyuan Yan ${ }^{1,2}$, Jui-Jung Liao ${ }^{1}$, Ching-Hui Shih ${ }^{3}$ \\ ${ }^{1}$ Nankai University (China) \\ ${ }^{2}$ Shandong Yingcai University (China) \\ ${ }^{3}$ Asia University (Taiwan) \\ Yan5559@126.com, rollanliao@gmail.com, chshib168@.gmail.com
}

Received: November 2014

Accepted: January 2015

\section{Abstract:}

Purpose: The goal of this study was to propose the multi-agent mechanism to forecast the corporate financial distress.

Design/methodology/approach: This study utilized numerous methods, namely random subspace method, discriminant analysis and decision tree to construct the multi-agent forecasting model.

Findings: The study shows a superior forecasting performance.

Originality/value: The use of multi-agent model to predict the corporate financial distress.

Keywords: hybrid model, multi-agent mechanism, financial distress, intangible assets, risk management

\section{Introduction}

Financial securities firms in Taiwan have developed quickly in recent years, with the ability to provide more information for decision makers to conduct financial investments. They now offer numerous types of financial products, such as stocks, options, futures, bonds, mutual funds, 
derivatives, etc. For Taiwanese, stock investing is the most widely adopted form among all of investment strategies. Unfortunately, the stock market is full of uncertainty, volatility, and risk, and most investors merely realize that a firm is encountering financial difficulty after negative financial statements (i.e., balance sheet, income statement, cash flow, and owners' equity) have been announced publicly (Xu \& Wang, 2009). Therefore, precisely predicting a firm's financial distress plays an essential part in today's society, because of its great importance to publicly traded firms, interested stakeholders, and even the financial economy of a country (Chen \& Du, 2009; Wanke, Barros \& Faria, 2014; Lin \& Hsu, 2014). An effective financial distress prediction mechanism helps managers make a reliable judgment and a suitable operating strategy with limited operating risk, thus increasing future earnings and the possibility of sustainable development (Shi, Guan \& Xie, 2014). Even 1\% improvement in a mechanism's forecasting performance will help prevent great losses to firms and individuals (Hand \& Henley, 1997). For this reason, predicting financial distress has become much more important and caught numerous researchers' attention due to economic markets slowing down or even going into a depression (Lin, 2009).

Hua, Wang, Xu, Zhang and Liang (2007) indicates that financial distress occurs when a corporate suffers considerable losses or when the corporate becomes insolvent from total liabilities that are greater than its total assets. It is widely accepted that financial distress firms have poor debt management, improper capital budgets, and bad investment portfolios and operating strategies in contrast to non-financial distress firms. The basic assumption underlying financial distress forecasting is that a firm's financial statement can be used to represent its operating characteristics. Thus, numerous financial pre-warning mechanisms have been proposed to forecast financial distress by implementing ratio analysis and data gathered from financial statements. The proper technique adopted to construct a pre-warning model is another critical task that considerably impacts the model's forecasting performance. Numerous researchers have applied statistical methods, such as univariate analysis, multivariate analysis, multiple discriminant analysis, multiple regression, logistic regression, factor analysis, and stepwise regression (Beaver, 1966; Altman, 1968; Meyer \& Pifer, 1970; Deakin, 1972; Blum, 1974; Altman, Haldeman \& Narayanan, 1977; Ohlson, 1980; Zmijewski, 1984; Dimitras, Zanakis \& Zopounidis, 1996; Laitinen \& Laitinen, 2000; Chuvakhin \& Gertmenian, 2003), to construct financial distress prediction models and have exhibited a satisfactory job in the forecasting task. Unfortunately, the strict assumptions of conventional statistical techniques, such as normality, linearity, independence among predictor variables, and pre-existing functional forms relating to the decision variables and condition variables, greatly deteriorate their practical application in the real world (Hua et al., 2007).

With the great development of information technologies, artificial intelligence (AI) techniques, and machine learning (ML) techniques, a new field of intelligent data analysis tools in recent years has begun to appear and quickly grow under the embarrassing background of abundant data and poor knowledge (Sun \& Li, 2009; Haque \& Hasin, 2012). New developments have 
also brought forth exhaustive research on a pre-warning mechanism for financial crisis forecasting without satisfying the conventional statistical assumptions and have shown very inspiring results in their empirical applications. Although the aforementioned techniques can be implemented to assess financial risk, the ability to discriminate non-financial distress firms from financial distress firms still needs further improvement. The motivation for a multi-agent mechanism is to make use of the outcomes determined by numerous dissimilar models instead of just utilizing a single one, such that the forecasting outcome can be less biased and the possibility of an unsuitable judgment can be prevented (Lin, Chang \& Hsu, 2013).

The effectiveness of a multi-agent mechanism depends on two elements: preciseness and diversity of the base instrument/model. Among the artificial intelligence techniques, decision tree (DT) is widely utilized for various reasons:

- its forecasting outcome can be easily attained for a decision maker,

- the forecasting model construction by DT has no pre-defined assumption about the underlying distribution, and

- the forecasting model construction by DT is faster than other artificial intelligence techniques.

Thus, we select DT with its superior generalization ability as a base classifier. How to generate a diverse outcome is another critical task that can be solved by the technique called the random subspace method (RSM) (Ho, 1998). The utilization of dissimilar space for multi-agent mechanism establishment has been extensive in recent research. Ho (1998) indicated that RSM is able to facilitate forecasting accuracy and decreases the generalization error. The basic idea of RSM, rooted in the theory of stochastic discrimination (Kleinberg, 2000), has some points that are the same a bagging, but instead of sampling examples it samples subspaces (Skurichina \& Duin, 2001; García-Pedrajas \& Ortiz-Boyer, 2008). It has been successfully implemented on numerous research domains.

Although RSM has shown that the random feature selection enhances forecasting accuracy without affecting error rates, one critical drawback is that the selected attributes that are decided randomly do not guarantee that they carry the necessary discrimination information. In such a case, poor base instruments are established that damage the multi-agent mechanism. Discriminant analysis (DA) is thus used to handle this related problem. In other words, the original attributes undergo RSM so as to generate numerous subsets and then DA picks up the essential attributes from each subset for predicting model construction. By executing these two pre-processing techniques, the forecasting model's performance can be enhanced and computational cost can be eliminated. 
With the speed in the growth and development of electronic commerce, the economic structure of many developed countries has undergone significant changes from that of a traditional economy to a knowledge economy. In the former, physical assets are the essential factors to determine a corporate's value, but obviously not so in a knowledge economy. In a modern economy (knowledge economy), the essential part in the value-creating process is intangible assets (Guthrie \& Petty, 2000; Guthrie, 2001), which encompass a corporate's dynamic ability generated from its knowledge resources and core competences (such as employee professional skills, organizational structure, R\&D innovation, brand, and market share). Following Gleason and Klock (2006), this study takes advertising expenditure and R\&D expenditure as proxies for intangible capital/assets and uses them to set up an effective financial crisis prediction model.

The rest of the paper is structured as follows. Section 2 introduces the methodologies used in this study. Section 3 presents a review of the data from our empirical work and the experimental decisions. Finally, section 4 offers conclusions.

\section{Methodologies}

\subsection{Random Subspace Method: RSM}

The random subspace method (RSM) is a multi-agent construction method introduced by Ho (1998) that may benefit from both utilizing random subspaces for establishing the base instrument and aggregating the base instruments. When the dataset is full of redundant, useless, and irrelevant attributes, one may achieve a better base instrument in random subspaces than in the raw attribute space (Ho, 1998). A greater detailed illustration in Ho (1998), and Figure 1 presents the pseudo-code for RSM (Wang \& Ma, 2011; Wang, Hao, Ma \& Jiang, 2011).

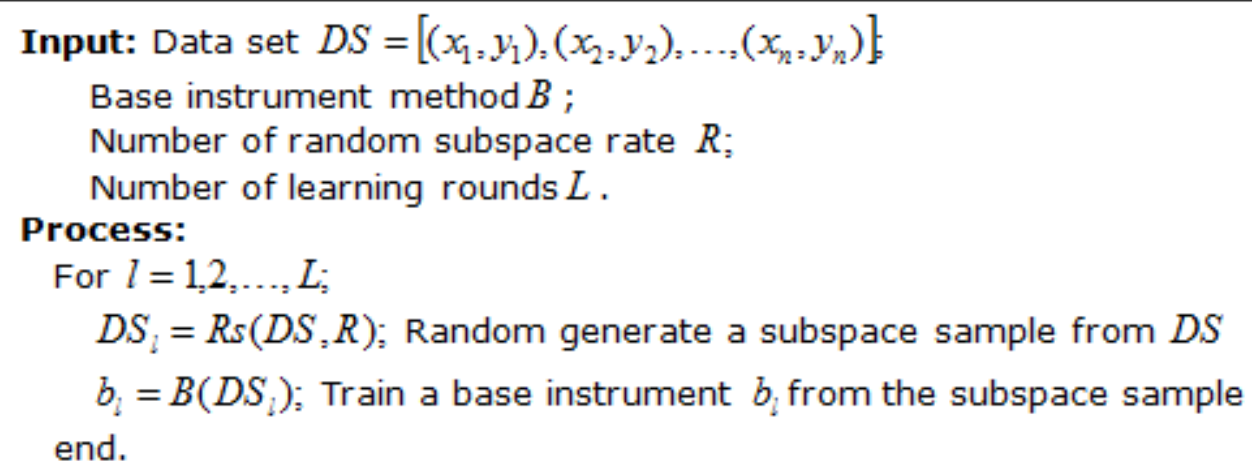




\subsection{Discriminant Analysis: DA}

Discriminant analysis (DA) is an effective classification approach (Otto, 1998), and its fundamental concept is to identify a transformation matrix $K$ that maximizes the ratio of between-class variance $O_{b}$ to the within-class variance $O_{w}$ under all kinds of data structure in order to reach maximum separation. The ratio of the between-class variance to the withinclass variance is represented as:

$$
G(K)=k^{T} O_{b} A / k^{T} O_{w} A
$$

Equations (2) and (3) represent the between-class variance and within-class variance, respectively.

$$
\begin{gathered}
O_{b}=\sum_{i=1}^{q} R_{i}\left(\alpha_{i}-\alpha\right)\left(\alpha_{i}-\alpha\right)^{T} \\
O_{w}=\sum_{i=1}^{q} R_{i} \sum_{j=1}^{n_{i}}\left(x_{j}^{i}-\alpha_{i}\right)\left(x_{j}^{i}-\alpha_{i}\right)^{T}
\end{gathered}
$$

Here, $q$ denotes the total number of classes, $n_{i}$ represents the number of samples in class $i$, the probability of class $i$ is $p_{i}$, the $j$-th training sample vector of class $i$ is expressed as $x_{i}^{j}$, and $\alpha$ is the mean of all samples. By solving the generalized eigenvalue problem of $O_{b}$ and $O_{w}$, the transformation matrix $K$ can be decided.

$$
O_{w}^{-1} O_{b} A=\alpha A
$$

Here, the generalized eigenvalue is $\alpha$. Since the rank of the matrix $O_{b}$ is $q-1$, there are only $q-1$ non-zero eigenvalues in relation to Equation (4).

\subsection{Decision Trees}

The most commonly implemented artificial intelligence (AI) technique in the category of data mining and machine learning is decision trees (DT) and it can be used to handle two main types of problems: one is the regression problem and the other is the classification problem. Due to the nature of easy-to-implement and comprehension, it has become gradually more popular than other AI techniques. Kim and Uoneja (2014) stated that C4.5, one of the popular types for constructing a DT model, generates DT by an assessing criteria namely information gain (IG) or by partitioning the tree at a specific stage. This technique starts with a minimal tress and evaluates the attributes that provides the most useful partition of the training cases. The mathematical format of gain ratio was represented in Eq. (5) and it is the assessing criteria for splitting in the C4.5 DT technique. 


$$
G\left(a_{g}\right)=\left[\sum_{h=1}^{k}-\left(\frac{B_{Y_{h}}^{(u)}}{B^{(u)}}\right) \log \left(\frac{B_{Y_{h}^{(u)}}^{(u)}}{B^{(u)}}\right)\right]-\left[\sum_{s=1}^{s}\left(\frac{B^{(s)}}{B^{(u)}}\right) \sum_{h=1}^{k}-\left(\frac{B_{Y_{h}}^{(s)}}{B^{(s)}}\right) \log \left(\frac{B_{Y_{h}}^{(s)}}{B^{(s)}}\right)\right],
$$

where the first term and the second term in the formula represent the entropy at the parent node and the entropy at the child node, respectively. The difference between the two expresses the information and attributes that generate the gain ratio, and the largest gain ratio among all gain ratios is used to handle the partition task. Each child node is treated again as a new tree, and the process repeats until there is no misclassification in the training data (Kim \& Upneja, 2014).

\subsection{Multi-Agent Hybrid Mechanism (MAHM)}

Figure 2 illustrates this research's multi-agent hybrid mechanism (MAHM) for financial risk management. The research data were collected form public websites. Most related works merely take financial ratios as input variables to construct their forecasting model. However, financial variables are unable to illustrate the full aspect of the corporate operating performance in a knowledge-intensive economy, whereby the corporate core competences are intangible assets. A corporate with a large proportion of intangible assets has a higher possibility of gaining considerable wealth and seeing strengthened competitiveness in the future. Thus, this study takes into account a firm's intangible assets.

The collected data may be contaminated by some degree of error and mistakes that could mislead the research findings. We adopt a data cleaning procedure to eliminate the effects due to outliers and extreme values and also omit missing values. After going through data cleaning, RSM is then implemented. It randomly selects a group of low dimensionality subspaces from the whole space of original high dimensional features so as to generate a diverse outcome and to eliminate computational burden. One critical weakness of RSM is that the selected attributes picked up randomly do not promise that they in fact have the proper information content to prevent the discriminated ability. An effective way to handle this problem is through feature selection, which aims at determining the informative features in order to represent the original high dimensional feature vector, while at the same time discarding unrepresentative, redundant, or useless information that seriously deteriorates the model's forecasting performance (Yang \& Ong, 2012). 
Normally, the original features undergoing the feature selection procedure yield benefits that:

- facilitate computational efficiency,

- eliminate calculation cost,

- alleviate the curse of dimensionality, and

- improve generalization ability (Sun, Jia \& Li, 2011; Wu \& Hsu, 2012; Maldonado, Weber \& Famili, 2014; Sun, Li, Huang \& He, 2014).

DA has demonstrated its superior performance in pattern recognition and feature selection and thus is adopted herein to handle the feature selection task.

Although conventional statistical approaches and artificial intelligence algorithms can be implemented to establish a financial pre-warning model, their forecasting performance still needs further improvement. A multi-agent mechanism is a promising way to sound out the prediction performance, and its usefulness depends on two core elements: preciseness and diversity. DT has shown its outstanding generalization ability and thus is taken as a base instrument to establish a multi-agent hybrid mechanism (MAHM). Diverse outcomes can be achieved by adjusting the inherent parameters. By modifying the inherent parameters of MAHM and aggregated into one final result, the forecasting outcome will be less biased and more accurate.

To test the usefulness of the proposed MAHM, this study takes it as a benchmark for comparison with other models, such as neural network (NN), Bayes network (BN), rough set theory (RST), and logistic regression (LR). To ensure that the results do not happen by chance, we perform the significance of the forecasting outcomes by means of a statistical test - that is, the independent sample t-test. The empirical results present that the proposed MAHM is a promising alternative for financial distress forecasting and yields valuable and comprehensible decision rules for stakeholders, managers, investors, and related parties to make a reliable judgment. Comprehensibility is important whenever discovered knowledge will be used for supporting a decision made by human users. The decision rules generated from MAHM are represented in an if-then format that is intuitive and easy to realize. The rules can be taken as a guideline to adjust a personnel investment portfolio and to modify capital allocation. 


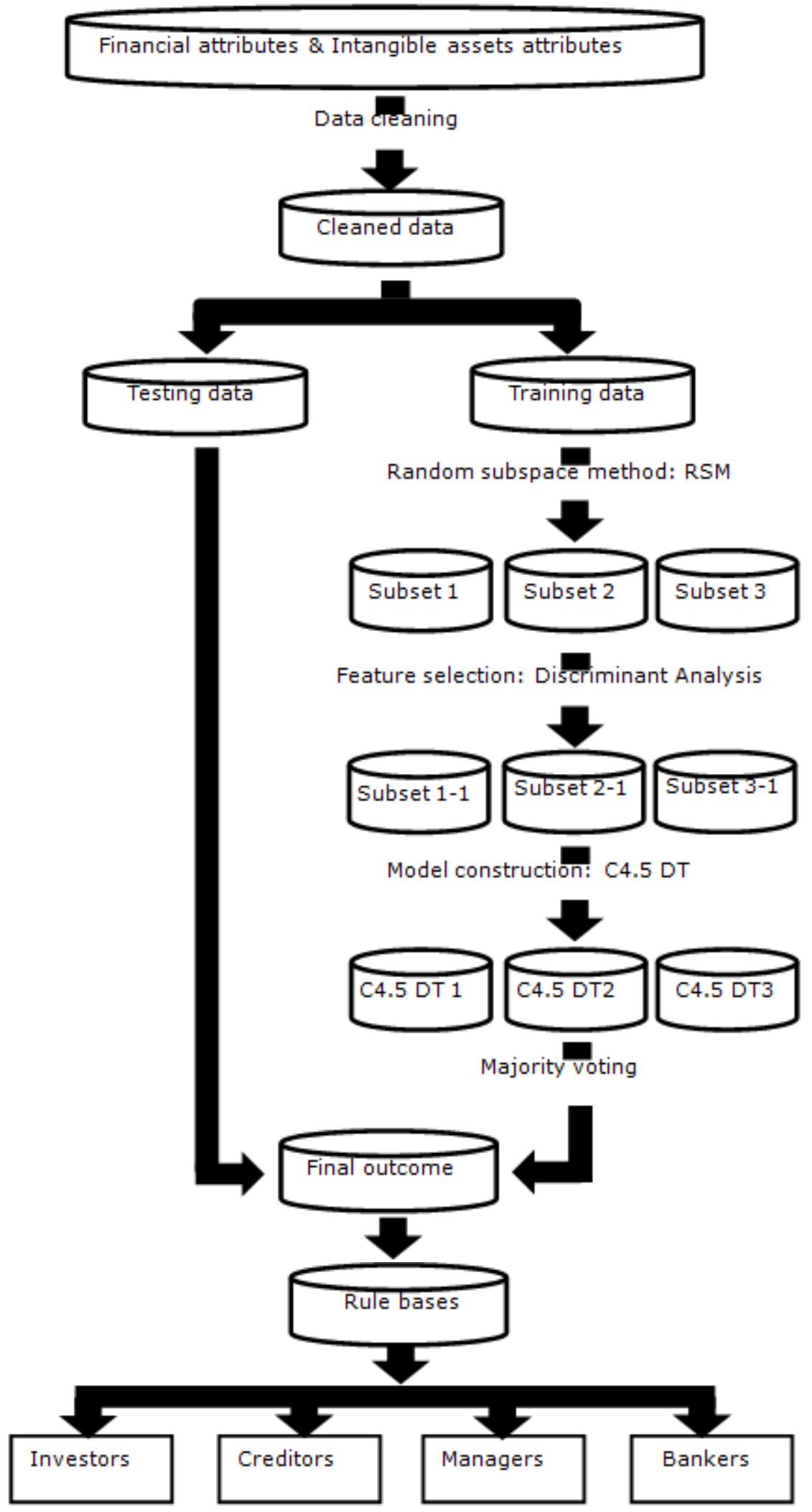

Figure 2. The flowchart of the multi-agent hybrid mechanism: MAHM 


\section{Empirical Work and Experimental Decision}

\subsection{Data}

The data in this study contain 900 listed corporates in the Taiwan stock market from 2010 to 2013, including 90 financial crisis corporates and 810 non-financial crisis corporates. The Taiwan Stock Exchange (TSE) has published indications or judgments of a financial crisis for the 90 financial crisis corporates. All financial ratios and intangible assets come from financial reports, such as income statements, balance sheets, and cash flows, as well as annual reports from Taiwan Economic Journal (TEJ) and the exchange. Through the literature review, we examine 12 ratios (i.e., 10 financial features and 2 intangible assets features), which are presented in Table 1 (Collins \& Green, 1972; Spathis, 2002; Ko \& Lin, 2006; Bose, 2006; Chandra, Ravi \& Bose, 2009).

\begin{tabular}{|c|c|c|c|}
\hline \multicolumn{2}{|r|}{ Financial attribute } & \multicolumn{2}{|r|}{ Intangible assets attribute } \\
\hline A1 & Net income to total assets & A11 & Advertising expenditure \\
\hline A2 & Earnings before interest and tax & A12 & R\&D expenditure \\
\hline A3 & Net income to sales & & \\
\hline A4 & Total debt to total assets & & \\
\hline $\mathbf{A 5}$ & Logarithm of total debt & & \\
\hline A6 & Working capital to total assets & & \\
\hline $\mathbf{A 7}$ & Total debt to total equity & & \\
\hline $\mathbf{A 8}$ & Long-term debt to total assets & & \\
\hline A9 & Current assets to current liabilities & & \\
\hline A10 & Quick assets to current liabilities & & \\
\hline
\end{tabular}

Table 1 . The description of each attribute

\subsection{Measuring Criteria}

Forecasting accuracy and error rates are essential assessing criteria in financial distress prediction. The assessing criteria normally consist of overall accuracy, type I error, and type II error. Each assessing criterion has its advantage and limitations. Thus, we prefer to utilize a combination of these assessing criteria, rather than just a single assessing criterion, so as to measure the model's forecasting performance. The definitions of these assessing criteria can be represented in a confusion matrix (see Table 2), and the mathematical formulations are shown in Equations (6)-(8).

\begin{tabular}{|c|c|c|}
\hline \multirow{2}{*}{ Situation } & \multicolumn{2}{|c|}{ Actual situation } \\
\cline { 2 - 3 } Positive prediction & True positive (TP) & Negative \\
\hline Negative prediction & False negative (FN) & True negitive (FP) \\
\hline
\end{tabular}

Table 2. The confusion matrix 


$$
\begin{gathered}
\text { Overall-accuracy }=(T P+T N)(T P+F P+F N+T N) \\
\text { Type I error }=(F N) /(T P+F N) \\
\text { Type II error }=(F P) /(F P+T N)
\end{gathered}
$$

\subsection{Results}

To examine the effectiveness of the multi-agent structure and feature selection approach DA (see Table 3), the study presents the outcomes under two scenarios:

- with and without multi-agent structure; and

- with and without feature selection.

The experimental results are in Tables 4-5. To ensure that the outcomes do not happen by chance, we examine the significance of the prediction outcomes by means of the independent sample t-test, with the statistical outcomes in Table 6 . According to our research finding, the multi-agent structure outperforms the singular structure. The finding is in response to prior research done by Sharkey (1996). The merit of the multi-agent structure complements any error made by the singular model. The model with the feature selection procedure not only can increase forecasting accuracy, but also can decrease both types of errors.

The study considers the financial ratios and also takes the features of intangible assets into consideration to construct the financial distress prediction model. To evaluate the effects of the intangible assets, this study performs the following measurements: (1) with and without intangible assets (IA). Table 7 shows the results. According to our research findings, the intangible assets not only help facilitate overall accuracy for the forecasting performance, but also eliminate the forecasting errors (type I errors and type II errors).

To test the usefulness of the introduced MAHM, we use three other popular prediction models in the experiment neural network (NN), Bayes network (BN), and logistic regression (LR) - with a cross-validation scheme. In k-fold cross-validation, we first separate the training data into subsets of equal size. One subset is then utilized to examine the model established from the remaining ( $\mathrm{k}-1)$ subsets. Thus, each instance of the whole set of the training data is forecasted once, and so the cross-validation forecasting quality is the percentage of data that are precisely discriminated. This can overcome the problem of over-fitting. This study also conducts five-fold cross-validation, with the results in Tables 8-9 indicating that the introduced MAHM still outperforms over the other models in terms of all assessing criteria. 
The base instrument of MAHM is DT, which can yield human readable rules for users as well as enhance the model's comprehensibility. This is very essential whenever extracted knowledge will be utilized for assisting users in making reliable judgments. Table 10 expresses the rules, which state that a financial distress firm usually has lower profitability, higher debt structure, and small R\&D investment in contrast to a non-financial distress firm.

\begin{tabular}{|c|c|c|c|}
\hline \multicolumn{2}{|r|}{ Financial attribute } & \multicolumn{2}{|r|}{ Intangible assets attribute } \\
\hline - & A1: Net income to total assets & $\square$ & A11: Advertising expenditure \\
\hline$\square$ & A2: Earnings before interest and tax & - & A12: $R \& D$ expenditure \\
\hline - & A3: Net income to sales & & \\
\hline - & A4: Total debt to total assets & & \\
\hline$\square$ & A5: Logarithm of total debt & & \\
\hline$\square$ & A6: Working capital to total assets & & \\
\hline$\square$ & A7: Total debt to total equity & & \\
\hline$\square$ & A8: Long-term debt to total assets & & \\
\hline$\square$ & A9: Current assets to current liabilities & & \\
\hline ㅁ & A10: Quick assets to current liabilities & & \\
\hline
\end{tabular}

Table 3. The description of selected attribute

\begin{tabular}{|c|c|r|r|}
\hline \multirow{2}{*}{ Condition } & \multicolumn{2}{|c|}{ With and without multi-agent structure (RSM+DA+DT v.s. DT) } \\
\cline { 2 - 4 } & Accuracy & Type I errors & \multicolumn{1}{c|}{ Type II errors } \\
\hline CV-1 & 90.44 v.s. 83.22 & 9.51 v.s. 16.79 & 10.00 v.s. 16.67 \\
\hline CV-2 & 90.11 v.s. 78.33 & 10.12 v.s. 21.98 & 7.78 v.s. 18.89 \\
\hline CV-3 & 91.67 v.s. 80.44 & 8.40 v.s. 19.63 & 7.78 v.s. 18.89 \\
\hline CV-4 & 90.22 v.s. 79.67 & 9.88 v.s. 20.12 & 8.89 v.s. 22.22 \\
\hline CV-5 & 91.33 v.s.79.89 & 9.01 v.s. 20.49 & 5.56 v.s.16.67 \\
\hline AVG. & 90.76 v.s. 80.31 & 9.38 v.s. 19.80 & 8.00 v.s. 18.67 \\
\hline
\end{tabular}

Table 4 . The results of scenario 1

\begin{tabular}{|c|c|r|r|}
\hline \multirow{2}{*}{ Condition } & \multicolumn{3}{|c|}{ With and without feature selection (RSM+DA+DT V.s. RSM+DT) } \\
\cline { 2 - 4 } & \multicolumn{1}{|c|}{ Accuracy } & Type I errors & \multicolumn{1}{c|}{ Type II errors } \\
\hline CV-1 & 90.44 v.s. 87.56 & 9.51 v.s. 12.35 & 10.00 v.s. 13.33 \\
\hline CV-2 & 90.11 v.s. 86.11 & 10.12 v.s. 13.83 & 7.78 v.s. 14.44 \\
\hline CV-3 & 91.67 v.s. 84.89 & 8.40 v.s. 15.80 & 7.78 v.s. 8.89 \\
\hline CV-4 & 90.22 v.s. 81.33 & 9.88 v.s. 19.26 & 8.89 v.s. 13.33 \\
\hline CV-5 & 91.33 v.s.82.67 & 9.01 v.s. 18.02 & 5.56 v.s.11.11 \\
\hline AVG. & 90.76 v.s.84.51 & 9.38 v.s. 15.85 & 8.00 v.s. 12.22 \\
\hline
\end{tabular}

Table 5 . The results of scenario 2

\begin{tabular}{|c|c|c|c|}
\hline \multirow{2}{*}{ Condition } & \multicolumn{3}{|c|}{ Scenario 1 (RSM+DA+DT V.S. DT) } \\
\hline & Accuracy & 100-Type I errors & 100-Type II errors \\
\hline AVG. & 90.76 v.s. 80.31 & 90.62 v.s. 80.20 & 92.00 v.s. 81.33 \\
\hline Statistic & $p$-value $=0.00$ & $p$-value $=0.00$ & $p$-value $=0.00$ \\
\hline \multirow{2}{*}{ Condition } & \multicolumn{3}{|c|}{ Scenario 2 (RSM+DA+DT V.S. RSM+DT) } \\
\hline & Accuracy & 100-Type I errors & 100-Type II errors \\
\hline AVG. & 90.76 v.s. 84.51 & 90.62 v.s. 84.12 & 92.00 v.s. 87.78 \\
\hline Statistic & $p$-value $=0.00$ & $p$-value $=0.00$ & p-value $=0.00$ \\
\hline
\end{tabular}

Table 6. The statistic result under two dissimilar scenarios 


\begin{tabular}{|c|r|r|r|}
\hline \multirow{2}{*}{ Condition } & \multicolumn{2}{|c|}{ With and without intangible assets attribute } \\
\cline { 2 - 4 } & \multicolumn{1}{|c|}{ Accuracy } & Type I errors & \multicolumn{1}{c|}{ Type II errors } \\
\hline CV-1 & 90.44 v.S. 80.89 & 9.51 v.S. 19.01 & 10.00 v.S. 20.00 \\
\hline CV-2 & 90.11 v.S. 78.56 & 10.12 v.S. 21.98 & 7.78 v.S. 16.67 \\
\hline CV-3 & 91.67 v.S. 77.78 & 8.40 v.S. 22.59 & 7.78 v.S. 18.89 \\
\hline CV-4 & 90.22 v.S. 81.56 & 9.88 v.S. 18.02 & 8.89 v.S. 22.22 \\
\hline CV-5 & 91.33 v.s.80.78 & 9.01 v.S. 18.64 & 5.56 v.S. 24.44 \\
\hline AVG. & 90.76 v.S.19.91 & 9.38 v.S. 20.05 & 8.00 v.S. 20.44 \\
\hline Statistics & p-value $=0.00$ & p-value $=0.00$ & p-value $=0.00$ \\
\hline
\end{tabular}

Table 7. The results

\begin{tabular}{|c|r|r|r|}
\hline Model (AVG) & \multicolumn{1}{|c|}{ Accuracy } & \multicolumn{1}{c|}{ Type I errors } & \multicolumn{1}{c|}{ Type II errors } \\
\hline MADT & 90.76 & 9.38 & 16.22 \\
\hline NN & 84.73 & 15.16 & 26.44 \\
\hline LR & 77.69 & 21.85 & 29.78 \\
\hline BN & 78.29 & 20.81 & 00 \\
\hline
\end{tabular}

Table 8 . The results

\begin{tabular}{|c|r|r|r|}
\hline Model (AVG) & Accuracy & 1-Type I errors & \multicolumn{1}{c|}{ 1-Type II errors } \\
\hline MAHM v.S. NN & P-value $=0.004$ & P-value $=0.004$ & P-value $=0.109$ \\
\hline MAHM v.S. LR & P-value $=0.000$ & P-value $=0.000$ & P-value $=0.001$ \\
\hline MAHM v.S. BN & P-value $=0.000$ & P-value $=0.000$ & P-value $=0.000$ \\
\hline
\end{tabular}

Table 9. The statistic examination

\begin{tabular}{|l|l|}
\hline Rule & \multicolumn{1}{c|}{ Illustration } \\
\hline No. 1 & If the "A3: NITA" is $>0.26$, then the situation is "non-distress" \\
\hline No. 2 & $\begin{array}{l}\text { If the "A3: NITA" is }<=0.26 \text {, and the "A1:NITA" is }<=0.04 \text {, then the situation is } \\
\text { "distress" }\end{array}$ \\
\hline No. 3 & $\begin{array}{l}\text { If the "A3: NITA" is }<=0.26, \text { the "A1:NITA" is }>0.04 \text { and the "A4:TDTA" is }>0.43, \\
\text { then the situation is "distress" }\end{array}$ \\
\hline No. 4 & $\begin{array}{l}\text { If the "A3: NITA" is }<=0.26, \text { the "A1:NITA" is }>0.04, \text { the "A4:TDTA" is }<=0.43, \\
\text { and the A12:R\&D is }>500000, \text { then the situation is "non-distress" }\end{array}$ \\
\hline No. 5 & $\begin{array}{l}\text { If the "A3: NITA" is }<=0.26, \text { the "A1:NITA" is }>0.04, \text { the "A4:TDTA" is }<=0.43, \\
\text { and the A12:R\&D is }<=500000, \text { then the situation is "non-distress" }\end{array}$ \\
\hline
\end{tabular}

Table 10. The decision rules derived from MAHM

\subsection{Sensitivity Test}

The majority of related works use one pre-decided database to make a final decision. To prevent unreliable judgments, we examine the proposed MAHM with another financial database (Pietruszkiewicz, 2008) to examine the model's practicability. Tables 11-12 list the results. The experimental results indicate that the introduced MAHM still performs a satisfactory job in financial distress prediction.

\begin{tabular}{|c|r|r|r|}
\hline Model (AVG) & Accuracy & \multicolumn{1}{c|}{ Type I errors } & \multicolumn{1}{c|}{ Type II errors } \\
\hline MADT & 88.25 & 10.47 & 13.21 \\
\hline NN & 79.25 & 19.38 & 22.32 \\
\hline LR & 72.33 & 27.66 & 27.68 \\
\hline BN & 69.50 & 34.84 & 25.54 \\
\hline
\end{tabular}

Table 11. The results 


\begin{tabular}{|c|c|r|r|}
\hline Model (AVG) & Accuracy & 100-Type I errors & 100-Type II errors \\
\hline MAHM v.S. NN & P-value $=0.000$ & P-value $=0.000$ & P-value $=0.000$ \\
\hline MAHM v.S. LR & P-value $=0.000$ & P-value $=0.000$ & P-value $=0.000$ \\
\hline MAHM v.S. BN & P-value $=0.000$ & P-value $=0.000$ & P-value $=0.000$ \\
\hline
\end{tabular}

Table 12. The statistic examination

\section{Conclusion}

The prediction of corporate financial distress is an important and challenging issue that has served as an impetus for many academic research studies over the past decades. While intangible assets are widely acknowledged to be essential elements when forecasting a corporate financial crisis, they are usually excluded from prior related early warning models. The objective of this study is to utilize the attributes of intangible assets as predictive variables and to propose a multi-agent hybrid mechanism, MAHM, to increase preciseness in the prediction of corporate financial distress. The introduced MAHM is grounded on the hybrid model that integrates multiple dissimilar base instruments into an aggregated outcome and has proved its superior forecasting performance. The fundamental idea behind the hybrid model is to complement the error made by a singular model.

How to increase the diversity of the hybrid model is a very essential task. Two pre-processing techniques, RSM and DA, have been conducted herein to generate the diverse outcomes. RSM picks up features randomly to enhance the hybrid model's diversity, but has a critical weakness in that the determined features may lack information content. Thus, DA is then executed to determine the essential features from the preprocessed subsets (i.e., the determined features by RSM) to construct the pre-warning model.

For verifying the applicability of the introduced MAHM, we compare it with other models under three scenarios:

- with and without a multi-agent structure;

- with and without a feature selection technique; and

- with and without an intangible asset feature.

According to the research findings, the warning model with a multi-agent structure (i.e., MAHM) outperforms the model without a multi-agent structure. The finding is in accordance with the basic idea of ensemble learning. The benefit of feature selection is that it not only eliminates computational cost, but also enhances data visualization and facilitates forecasting quality. 
This study further examines the effectiveness of intangible asset attributes in a knowledge economy. The results indicate that the intangible assets can increase forecasting accuracy and decrease both types of errors. The potential implication is that a corporate with a large amount of intangible assets has a lower possibility of encountering financial troubles and has a higher possibility of achieving considerable profit in the future as well as having a sound and sustainable operation ability. Finally, the proposed MAHM can generate intuitive rules for decision makers. Decision makers can take the rules as a textbook to modify their operating strategies and to adjust their firm's capital structure to survive in a turbulent economic market.

Two possible directions for future works emerge from this present research. One direction involves implementing the introduced MAHM on other databases to examine the model's effectiveness. A second direction is to utilize other feature selection techniques (such as kernel discriminant analysis: KDA, kernel principal component analysis: KPCA) to increase forecasting performance.

\section{Acknowledgments}

This paper is supported by National Natural Science Foundation of China "Research on the Incentive and Risk Control of IT Service Supply Chain Based on the SaaS" (Grant No. 71172072).

\section{References}

Altman, E.I. (1968). Financial ratios, discriminant analysis, and the prediction of corporate bankruptcy. Journal of Finance, 23, 589-609. http://dx.doi.org/10.1111/j.1540-6261.1968.tb00843.x

Altman, E.I., Haldeman, R.G., \& Narayanan, P. (1977). Zeta analysis. Journal of Banking and Finance, 1, 29-51. http://dx.doi.org/10.1016/0378-4266(77)90017-6

Beaver, W. (1966). Financial ratios as predictors of failure, empirical research in accounting: Selected studied. Journal of Accounting Research, 4, 71-111. http://dx.doi.org/10.2307/2490171

Blum, M. (1974). Failing company discriminant analysis. Journal of Accounting Research, 12, 1-15. http://dx.doi.org/10.2307/2490525

Bose, I. (2006). Deciding the financial health of dot-coms using rough sets. Information and Management, 43, 835-846. http://dx.doi.org/10.1016/j.im.2006.08.001

Collins, R.A., \& Green, R.D. (1972). Statistical methods for bankruptcy forecasting. Journal of Economics and Business, 32, 349-354. 
Chuvakhin, N., \& Gertmenian, L.W. (2003). Predicting bankruptcy in the WorldCom age. Journal of Contemporary Business Practice, 6, 1-8.

Chandra, D.K., Ravi, V., \& Bose, I. (2009). Failure prediction of dotcom companies using hybrid intelligent techniques. Expert Systems with Applications, 36, 4830-4837.

http://dx.doi.org/10.1016/j.eswa.2008.05.047

Chen, W.S., \& Du, Y.K. (2009). Using neural networks and data mining techniques for the financial distress prediction model. Expert Systems with Applications, 36, 4075-4086. http://dx.doi.org/10.1016/j.eswa.2008.03.020

Deakin, E.B. (1972). A discriminant analysis of predictors of business failure. Journal of Accounting Research, 10, 167-179. http://dx.doi.org/10.2307/2490225

Dimitras, A.I., Zanakis, S.H., \& Zopounidis, C. (1996). A survey of business failures with an emphasis on prediction methods and industrial applications. European Journal of Operational Research, 90, 487-513. http://dx.doi.org/10.1016/0377-2217(95)00070-4

García-Pedrajas, N., \& Ortiz-Boyer, D. (2008). Boosting random subspace method. Neural Networks, 21, 1344-1362. http://dx.doi.org/10.1016/j.neunet.2007.12.046

Gleason, K.I., \& Klock, M. (2006). Intangible capital in the pharmaceutical and chemical industry. The Quarterly Review of Economics and Finance, 46, 300-314.

http://dx.doi.org/10.1016/j.qref.2005.03.001

Guthrie, J. (2001). The management, measurement and the reporting of intellectual capital. Journal of Intellectual Capital, 2, 27-41. http://dx.doi.org/10.1108/14691930110380473

Guthrie, J., \& Petty, R. (2000). Intellectual capital: Australian annual reporting practices. Journal of Intellectual Capital, 1, 241-251. http://dx.doi.org/10.1108/14691930010350800

Hand, D.J., \& Henley W.E. (1997). Statistical classification methods in consumer credit scoring: a review. Journal of the Royal Statistical Society: Series A, 160, 523-541.

http://dx.doi.org/10.1111/j.1467-985X.1997.00078.x

Haque, K.Md.A., \& Hasin, Md.A.A. (2012). Genetic algorithm for project time-cost optimization in fuzzy environment. Journal of Industrial Engineering and Management, 5, 364-381. http://dx.doi.org/10.3926/jiem.410

Hua, Z., Wang, Y., Xu, X., Zhang, B., \& Liang, L. (2007). Predicting corporate financial distress based on integration of support vector machine and logistic regression. Expert Systems with Applications, 33, 434-440. http://dx.doi.org/10.1016/j.eswa.2006.05.006 
Ho, T.K. (1998). The random subspace method for constructing decision forests. IEEE Transactions on Pattern Analysis and Machine Intelligence, 20, 832-844.

http://dx.doi.org/10.1109/34.709601

Kim, S.Y., \& Upneja, A. (2014). Predicting restaurant financial distress using decision tree and Ada Boosted decision tree models. Economic Modelling, 36, 354-362.

http://dx.doi.org/10.1016/j.econmod.2013.10.005

Ko, P.C., \& Lin P.C. (2006). An evolution-based approach with modularized evaluations to forecast financial distress. Knowledge-Based Systems, 19, 84-91.

http://dx.doi.org/10.1016/j.knosys.2005.11.006

Kleinberg, E. (2000). On the algorithmic implementation of stochastic discrimination. IEEE Transactions on Pattern Analysis and Machine Intelligence, 22, 473-490.

http://dx.doi.org/10.1109/34.857004

Laitinen, E.K., \& Laitinen, T. (2000). Bankruptcy prediction application of the Taylor's expansion in logistic regression. International Review of Financial Analysis, 9, 327-349. http://dx.doi.org/10.1016/S1057-5219(00)00039-9

Lin, T.H. (2009). A cross model study of corporate financial distress prediction in Taiwan: Multiple discriminant analysis, logit, probit and neural networks models. Neurocomputing, 72, 3507-3516. http://dx.doi.org/10.1016/j.neucom.2009.02.018

Lin, S.J., Chang, C., \& Hsu, M.F. (2013). Multiple extreme learning machines for a two-class imbalance corporate life cycle prediction. Knowledge-Based Systems, 39, 214-223. http://dx.doi.org/10.1016/j.knosys.2012.11.003

Lin, S.J., \& Hsu, M.F. (2014). Enhanced risk management by an emerging multi-agent architecture. Connection Science, 26, 245-259. http://dx.doi.org/10.1080/09540091.2014.908821

Maldonado, S., Weber, R., \& Famili, F. (2014). Feature selection for high-dimensional classimbalanced data sets using Support Vector Machines. Information Sciences, 286, 228-246. http://dx.doi.org/10.1016/j.ins.2014.07.015

Meyer, P.A., \& Pifer, H. (1970). Prediction of bank failures. Journal of Finance, 25, 853-868. http://dx.doi.org/10.1111/j.1540-6261.1970.tb00558.x

Ohlson, J.A. (1980). Financial ratios and the probabilistic prediction of bankruptcy. Journal of Accounting Research, 18, 109-131. http://dx.doi.org/10.2307/2490395

Otto, M. (1998). Chemometrics, Statistics and Computer Application in Analytical Chemistry. Weinheim, Germany: Wiley VCH. 
Pietruszkiewicz, W. (2008). Dynamical systems and nonlinear Kalman filtering applied in classification. Proceedings of 7th IEEE International Conference on Cybernetic Intelligent Systems, 263-268.

Sharkey, A.J. (1996). On combining artificial neural nets. Connection Science, 8, 299-314. http://dx.doi.org/10.1080/095400996116785

Shi, Y., Guan, Z., \& Xie, X. (2014). Risk evaluation model building of logistics financial business for the bank and empirical research. Journal of System and Management Sciences, 4, 53-61.

Spathis, C. (2002). Detecting false financial statements using published data: some evidence from Greece. Management Auditing Journal, 17, 179-191.

http://dx.doi.org/10.1108/02686900210424321

Sun, J., Jia, M., \& Li, H. (2011). AdaBoost ensemble for financial distress prediction: An empirical comparison with data from Chinese listed companies. Expert Systems with Applications, 38, 9305-9312. http://dx.doi.org/10.1016/j.eswa.2011.01.042

Sun, J., Li, H., Huang, Q.H., \& He, K.Y. (2014). Predicting financial distress and corporate failure: A review from the state-of-the-art definitions, modeling, sampling, and featuring approaches. Knowledge-Based Systems, 57, 41-56. http://dx.doi.org/10.1016/j.knosys.2013.12.006

Sun, J., \& Li, H. (2009). Financial distress prediction based on serial combination of multiple classifiers. Expert Systems with Application, 36, 8659-8666.

http://dx.doi.org/10.1016/j.eswa.2008.10.002

Skurichina, M., \& Duin, R.P.W. (2001). Bagging and the random subspace method for redundant feature spaces. In J. Kittler, R. Poli (Eds.), Proceedings of the second international workshop on multiple classifier systems MCS, 1-10. http://dx.doi.org/10.1007/3-540-48219-9_1

Wang, G., Hao, J., Ma, J., \& Jiang, H. (2011). A comparative assessment of ensemble learning for credit scoring. Expert Systems with Applications, 38, 223-230.

http://dx.doi.org/10.1016/j.eswa.2010.06.048

Wang, G., \& Ma, J. (2011). Study of corporate credit risk prediction based on integrating boosting and random subspace. Expert Systems with Applications, 38, 13871-13878.

Wanke, P., Barros, C.P., \& Faria, J.R. (2015). Financial distress drivers in Brazilian banks: A dynamic slacks approach. European Journal of Operational Research, 240, 258-268. http://dx.doi.org/10.1016/j.ejor.2014.06.044

Wu, T.C., \& Hsu, M.F. (2012). Credit risk assessment and decision making by a fusion approach. Knowledge-Based Systems, 35, 102-110. http://dx.doi.org/10.1016/j.knosys.2012.04.025 
Xu, X., \& Wang, Y. (2009). Financial failure prediction using efficiency as a predictor. Expert Systems with Applications, 36, 366-373. http://dx.doi.org/10.1016/j.eswa.2007.09.040

Yang, J.B., \& Ong, C.J. (2012). An Effective Feature Selection Method via Mutual Information Estimation. IEEE Transactions on Systems, Man, and Cybernatic, 42, 1550-1559. http://dx.doi.org/10.1109/TSMCB.2012.2195000

Zmijewski, M.E. (1984). Methodological issues related to the estimation of financial distress prediction models. Journal of Accounting Research, 2, 59-82. http://dx.doi.org/10.2307/2490859

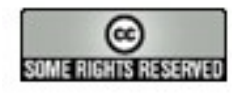

Article's contents are provided on a Attribution-Non Commercial 3.0 Creative commons license. Readers are allowed to copy, distribute and communicate article's contents, provided the author's and Journal of Industrial Engineering and Management's names are included. It must not be used for commercial purposes. To see the complete license contents, please visit http://creativecommons.org/licenses/by-nc/3.0/. 